\title{
ОЦЕНКА РАСПРЕДЕЛЕНИЯ КАДМИЯ \\ В ОБЬЕКТАХ ЭКОЛОГИЧЕСКОЙ СИСТЕМЫ И БИОЦЕНОЗАХ НА ПРИМЕРЕ ЦЕНТРАЛЬНОЙ ЗОНЫ ОРЕНБУРЖЬЯ
}

\author{
Е.В. Сальникова *, А.Н. Сизенцов, В.И. Пелих, Я.А. Сизенцов, Т.Ф. Тарасова \\ Оренбургский государственный университет, 460013, г. Оренбург, пр. Победы, 13 \\ *e-mail: salnikova_ev@mail.ru
}

РЕЗЮМЕ. Ежегодно увеличивающийся уровень антропогенной нагрузки, связанный с возрастающей урбанизацией и техногенной нагрузкой, негативно влияет на экологические системы и биоценозы. Одним из наиболее опасных факторов такого воздействия является накопление в окружающей среде ксенобиотических элементов. Среди токсических элементов одним из наиболее опасных является кадмий, который не только обладает высоким уровнем кумулятивного эффекта, но и выраженным антагонизмом с рядом жизненно важных эссенциальных элементов. Представлены данные распределения данного элемента в структуре цепи экологического взаимодействия вода-почва-растение-животное-человек на примере центральной зоны Оренбургской области. Экспериментально установлено наличие выраженной аккумуляции кадмия в почвенных образцах и биосубстратах сельскохозяйственных животных; следует отметить, что уровень кадмия во всех исследуемых образцах находился в пределах биологически допустимого уровня.

КЛЮЧЕВЫЕ СЛОВА: кадмий, биоаккумуляция, биоценоз, биосубстраты.

\section{ASSESSMENT OF THE DISTRIBUTION OF CADMIUM IN OBJECTS OF THE ECOLOGICAL SYSTEM AND BIOCENOSES ON THE EXAMPLE OF THE CENTRAL ZONE OF THE ORENBURG REGION}

\author{
E.V. Salnikova*, A.N. Sizentsov, V.I. Pelikh, Ya.A. Sizentsov, T.F. Tarasova \\ Orenburg State University, 13, Pobedy ave, 460018, Orenburg, Russia \\ *e-mail: salnikova_ev@mail.ru
}

\begin{abstract}
The annually increasing level of anthropogenic load associated with increasing urbanization and technogenic load negatively affects ecological systems and biocenoses in particular. One of the most dangerous factors of such impact is the accumulation of xenobiotic elements in the environment. Among the toxic elements, one of the most dangerous is cadmium, which not only has a high level of cumulative effect, but also pronounced antagonisms with a number of vital essential elements. In our work, we present the data on the distribution of this element in the structure of the chain of ecological interaction water-soil-plant-animal-human on the example of the central zone of the Orenburg region. The presence of a pronounced accumulation of cadmium in soil samples and biosubstrates of farm animals was experimentally established; it should be noted that the level of cadmium in all studied samples was within the biologically acceptable level.

KEYWORDS: cadmium, bioaccumulation, biocenosis, biosubstrates.
\end{abstract}

\section{ВВЕДЕНИЕ}

Ежегодно увеличивающийся уровень антропогенной нагрузки, связанный с возрастающей урбанизацией и техногенной нагрузкой, негативно влияет на экологические системы и биоценозы. Накопление в окружающей среде ксенобиотических элементов является одним из наиболее опасных факторов такого воздействия. Кадмий - одигн из наиболее опасных токсических элементов который не только обладает высоким уровнем кумулятивного эффекта, но и выраженным антагонизмом с рядом жизненно важных эссенциальных элементов.

Цель работы - оценка распределения кадмия в объектах экологической системы и биоценозах на примере центральной зоны Оренбургской области.

\section{МАТЕРИАЛЫ И МЕТОДЫ}

В качестве объектов исследования использованы вода, почва, пшеница, биосубстраты (почки, сердце, печень, мышцы) сельскохозяйственных животных и волосы жителей, постоянно проживающих в анализируемой зоне. Известно, что волосы являются не только легко отбираемым биологическим 
материалом, но и информативно показательным образчиком содержания как эссенциальных, так и токсических элементов (Скальный, 2003). Определение концентрации кадмия в исследуемых образцах проводили с использованием метода атомно-эмиссионной и масс-спектрометрии (АЭС-ИСП и МСИСП) на оборудовании Elan 9000 (Perkin Elmer, США) и Optima 2000 V (Perkin Elmer, США).

\section{РЕЗУЛЬТАТЫ И ОБСУЖДЕНИЕ}

Полученные данные (таблица) свидетельствуют о выраженной кумуляции исследуемого элемента в почвенных образцах с превышением ПДК на 20\% (допустимые значения 0,1 мг/кг). В остальных исследуемых объектах уровень кадмия не превышал биологически значимого уровня. Наибольшие концентрации содержания ксенобиотика зарегистрированы в биологических субстратах с максимальной аккумуляцией в сердце и органах, ответственных за детоксикацию организма (печень и почки).

Таблица. Анализ содержания кадмия в исследуемых образцах, мг/кг

\begin{tabular}{|c|c|c|c|c|c|}
\hline Показатель & Число объектов & Среднее (M) & Медиана (Ме) & Минимум (Min) & Максимум (Max) \\
\hline Вода & 195 & 0,002 & 0,001 & 0 & 0,008 \\
\hline Почва & 195 & 0,120 & 0,070 & 0,008 & 0,810 \\
\hline Пшеница & 195 & 0,003 & 0,003 & 0 & 0,011 \\
\hline \multicolumn{6}{|c|}{ Биосубстраты сельскохозяйственных животных } \\
\hline Почки & 30 & 0,040 & 0,040 & 0,020 & 0,070 \\
\hline Сердце & 30 & 0,056 & 0,058 & 0,010 & 0,102 \\
\hline Печень & 30 & 0,040 & 0,030 & 0,020 & 0,060 \\
\hline Мышцы & 30 & 0,006 & 0,006 & 0,001 & 0,020 \\
\hline \multicolumn{6}{|c|}{ Биологические образиь от жителей анализируемой территории (волосы) } \\
\hline Мужчины & 78 & 0,020 & 0,020 & 0,004 & 0,090 \\
\hline Женщины & 78 & 0,020 & 0,020 & 0,003 & 0,090 \\
\hline
\end{tabular}

П р и м е ч а н и е: биологически допустимый уровень (БДУ) $\mathrm{Cd}=1$.

\section{ВЫВОДЫ}

Содержание кадмия в образцах яровой пшеницы имеет допустимые значения исследуемого элемента. Следует отметить, что при проведении сравнительного анализа собственных данных с аналогичными литературными (Лебедев, Родионова, 2010) существенных различий между полученными результатами не установлено. Систематическое проведение подобных исследований позволяет не только оценить уровень экологического состояния отдельных территорий, но и своевременно проводить комплекс мероприятий, направленных на профилактику острых и хронических интоксикаций ксенобиотическими элементами.

\section{Список литературы}

1. Скальный А.В. Цинк и здоровье человека. Оренбург: РИС ГОУ ОГУ, 2003. 80 с.

2. Лебедев С.В., Родионова Г.Б. Экологическая оценка растительного сырья и продуктов питания различных природноклиматических зон Оренбургской области. Вестник ОГУ. 2010; 6(112): 152-155.

\section{References}

1. Skal'nyj A.V. Cink i zdorov'e cheloveka. Orenburg: RIC GOU OGU, 2003. $80 \mathrm{~s}$.

2. Lebedev S.V., Rodionova G.B. Jekologicheskaja ocenka rastitel'nogo syr'ja i produktov pitanija razlichnyh prirodno-klimaticheskih zon Orenburgskoj oblasti. Vestnik OGU. 2010; 6(112): 152-155. 